\title{
Proliferative signaling initiated in ACTH receptors
}

C.F.P. Lotfi ${ }^{1}$, A.P. Lepique ${ }^{1}$, F.L. Forti ${ }^{1}$, T.T. Schwindt ${ }^{1}$, C.B. Eichler ${ }^{1}$, M.O. Santos ${ }^{1}$, I.T. Rebustini ${ }^{1}$,

G.N.M. Hajj ${ }^{1}$, L. Juliano and H.A. Armelin ${ }^{1}$

\author{
${ }^{1}$ Departamento de Bioquímica, Instituto de Química, U niversidade de São Paulo, \\ São Paulo, SP, Brasil \\ ${ }^{2}$ Departamento de Biofísica, Escola Paulista de Medicina, \\ Universidade Federal do Estado de São Paulo, São Paulo, SP, Brasil
}

\author{
Correspondence \\ H.A. Armelin \\ Departamento de Bioquímica \\ Instituto de Q uímica, USP \\ 05508-990 São Paulo, SP \\ Brasil \\ E-mail: haarmeli@ quim.iq.usp.br \\ Presented at the First \\ International Meeting on Adrenal \\ Disease: Basic and Clinical \\ Aspects, Ribeirão Preto, SP, Brazil, \\ August 31-September 2, 1999. \\ Research supported by FAPESP and \\ CNPq to, respectively, H.A. Armelin \\ and L. Juliano. C.F.P. Lotfi is a \\ post-doctoral and A.P. Lepique, \\ F.L. Forti, T.T. Schwindt, \\ C.B. Eichler, M.O. Santos, \\ I.T. Rebustini and G.N.M. Hajj are \\ recipients of pre-doctoral \\ fellowships from FAPESP.
}

Received December 20, 1999 Accepted March 22, 2000

\section{Abstract}

This article reviews recent results of studies aiming to elucidate modes of integrating signals initiated in ACTH receptors and FGF2 receptors, within the network system of signal transduction found in Y1 adrenocortical cells. These modes of signal integration should be central to the mechanisms underlying the regulation of the $\mathrm{G}_{0} \rightarrow \mathrm{G}_{1} \rightarrow$ S transition in the adrenal cell cycle. FGF2 elicits a strong mitogenic response in $\mathrm{G}_{0} / \mathrm{G}_{1}$-arrested $\mathrm{Y} 1$ adrenocortical cells, that includes a) rapid and transient activation of extracellular signal-regulated kinases-mitogenactivated protein kinases (ERK-MAPK) (2 to $10 \mathrm{~min}$ ), b) transcription activation of c-fos, c-jun and c-myc genes (10 to $30 \mathrm{~min}$ ), c) induction of c-Fos and c-Myc proteins by $1 \mathrm{~h}$ and cyclin D1 protein by $5 \mathrm{~h}$, and d) onset of DNA synthesis stimulation within $8 \mathrm{~h}$. ACTH, itself a weak mitogen, interacts with FGF2 in a complex manner, blocking the FGF2 mitogenic response during the early and middle $\mathrm{G}_{1}$ phase, keeping ERK-MAPK activation and c-Fos and cyclin D1 induction at maximal levels, but post-transcriptionally inhibiting c-Myc expression. c-Fos and c-Jun proteins are mediators in both the strong and the weak mitogenic responses respectively triggered by FGF2 and ACTH. Induction of c-Fos and stimulation of DNA synthesis by ACTH are independent of PKA and are inhibited by the PKC inhibitor GF109203X. In addition, ACTH is a poor activator of ERK-MAPK, but c-Fos induction and DNA synthesis stimulation by ACTH are strongly inhibited by the inhibitor of MEK1 PD98059.

\section{Introduction}

Elucidation of the molecular mechanisms by which ACTH exerts its growth effects on adrenal cortex has defied investigators for decades. In the intact organism ACTH seems to be a mitogen, but in cultures of isolated adrenocortical cells ACTH behaves like a growth inhibitory hormone (1).

\author{
Key words \\ - ACTH \\ - FGF2 \\ - Signal transduction \\ - MAP kinases \\ - Early response genes
}

In recent years, we have reported for the first time a weak mitogenic response elicited by pulses of ACTH in cultures of the mouse Y1 adrenocortical tumor cell line (2,3). An investigation of the pathways activated by the $\mathrm{ACTH}$ receptors to trigger this mitogenic response in the $\mathrm{Y} 1$ adrenocortical cell system is likely to yield results of interest to understand the reactions underlying the 
ACTH growth effects on adrenal cortex.

Considerable attention has been recently given to mitogenic effects triggered by peptide hormones that activate $\mathrm{G}$ protein-coupled receptors. The majority of these studies has centered on determining whether, and how, signals initiated in $\mathrm{G}$ protein-coupled receptors can activate the mitogen-activated protein kinase (MAPK) cascades, particularly the one including the class of the extracellular signal-regulated kinases (ERK-MAPK) (4).

In Y1 adrenocortical cells, we started by showing that ACTH induces transcription of the fos and jun gene families $(5,6)$, a characteristic of peptide growth factors that bind to tyrosine kinase receptors initiating signals to activate the ERK-MAPK pathway. The Fos and Jun protein families consist of four (cFos, FosB, Fra1 and Fra2) and three gene products (c-Jun, JunB and JunD), respectively, that dimerize via a leucine zipper domain to form hetero- (Fos-Jun) and homodimers (Jun-Jun), that comprise the series of transcription factors denominated AP1 (7). AP1 factors seem to play a critical role in the control of $\mathrm{G}_{0} \rightarrow \mathrm{G}_{1} \rightarrow \mathrm{S}$ transition of the cell cycle. Quiescent $\mathrm{G}_{0}$-arrested fibroblasts exhibit very low levels of AP1 factors and upon stimulation by peptide growth factors, like fibroblast growth factor 2 (FGF2), rapidly induce the fos and jun genes in an ordered fashion (7). Blocking the induction of c-Fos and c-Jun proteins is sufficient to block the $\mathrm{G}_{0} \rightarrow \mathrm{G}_{1} \rightarrow \mathrm{S}$ transition in $\mathrm{G}_{0}$-arrested fibroblasts stimulated with FGF2 (8-10). Thus, $\mathrm{ACTH}$, inducing the fos and jun genes in Y1 adrenocortical cells, resembles FGF2 triggering the $\mathrm{G}_{0} \rightarrow \mathrm{G}_{1} \rightarrow \mathrm{S}$ transition in $\mathrm{G}_{0}$-arrested $3 \mathrm{~T} 3$ fibroblasts.

FGF2 is the prototype of the large family of fibroblast growth factors (11), presently consisting of 18 members (12) that are widely expressed in embryo, fetus and adult tissues of vertebrates and invertebrates. It has been recognized for years that forms of FGF play key roles in mitogenesis, cellular differentia- tion, angiogenesis and repair of tissue injury in the adult organism (11). In addition, reports of the last few years have involved molecular pathways commanded by FGFs in fundamental steps of embryo and fetal development such as left-right asymmetry determination in chick and mouse embryo (13), hepatogenesis in mouse embryo (14), development of the Drosophila tracheal system and the mouse lung (15), and development of the rat exocrine pancreas (16). In fact, it is becoming more and more clear that the FGF family of proteins and their respective set of receptors are major players governing the classical epithelial-mesenchymal interactions that underlie differentiation and organogenesis in the embryo. In the adult organism FGF forms persist throughout a number of different tissues as local paracrine and autocrine regulators of very basic biological processes like mitogenesis and cellular differentiation. The interaction between classical trophic hormones and FGFs, locally produced at the target cell level, is likely to be a major part of the molecular mechanisms by which trophic hormones regulate functions of target cells.

In adrenal cortex, FGF2 has long been considered a candidate for participating in the control of adrenal gland development in the fetus and also of growth and function in the adult adrenal cortex tissue (17). In this article we present an overview of our recent work focusing on the interaction between ACTH and FGF2 in cell cycle control of the Y1 adrenocortical tumor cell line. Y1 adrenocortical tumor cells behave in many respects like normal adrenocortical cells and have long been used as a model adrenocortical cell system (18). Particularly important is the fact that cultures of the $\mathrm{Y} 1$ clonal cell line are amenable to genetic approaches such as the classical somatic genetics (19) or the more recent DNA-mediated gene transfer approach (20). Thus, the study of the interaction between ACTH and FGF2 in Y1 adrenocortical cells is timely and methodologically 
promising. Our aim is to elucidate modes of integrating signals initiated in ACTH receptors and FGF2 receptors within the network system of signal transduction found in $\mathrm{Y} 1$ adrenocortical cells. These modes of signal integration should be central to the mechanisms underlying the regulation of the $\mathrm{G}_{0} \rightarrow \mathrm{G}_{1} \rightarrow \mathrm{S}$ transition in the adrenal cell cycle.

\section{FGF2 is a strong mitogen for Y1 adrenocortical cells}

In serum-free medium, $\mathrm{G}_{0} / \mathrm{G}_{1}$-arrested $\mathrm{Y} 1$ adrenocortical cells stimulated with bovine recombinant FGF2 (5-200 pM; short pulse, $30 \mathrm{~min}$ to $2 \mathrm{~h}$, or sustained treatment) display a mitogenic response consisting of the following sequential events: a) rapid and transient activation of $\mathrm{p} 42$ and $\mathrm{p} 44$ ERK-MAPK, peaking between 2 and $5 \mathrm{~min}$; b) transient transcription activation of the c-fos, c-jun, $j u n \mathrm{~B}$ and $\mathrm{c}-m y c$ genes, between 10 and 30 min; c) induction of c-Fos protein: $80 \%$ of the nuclei labeled with anti-c-Fos antibody by $1 \mathrm{~h}$ (control under $0.1 \%$ ); $\mathrm{d}$ ) induction of c-Myc protein: 70\% labeled nuclei with antic-Myc antibody by $2 \mathrm{~h}$ (control levels at $35 \%$ ); e) induction of the cyclin D1 protein: a sharp increase from negligible control levels detected by Western blot at $5 \mathrm{~h}$, and $\mathrm{f}$ ) the onset of DNA synthesis stimulation by $8 \mathrm{~h}$, showing $90 \%$ of BrdU-labeling index by 20 $\mathrm{h}$, whereas control levels increased linearly from $10 \%$ at zero time to $25 \%$ by $20 \mathrm{~h}$.

It is still unknown whether endogenous growth factors play an autocrine role in the growth control of $\mathrm{Y} 1$ adrenocortical cells. Nonetheless, total RNA of Y1 cells, probed with RT-PCR and specific primers, has yielded cDNA sequences of FGF2, FG5 and PDGF A, indicating that these peptide factors are produced by this adrenocortical cell line. In addition, serum-free medium conditioned with Y1 cells is rich in PDGF-like factors, but recombinant forms of PDGF AB and $\mathrm{BB}$ do not trigger a mitogenic response in $\mathrm{G}_{0} / \mathrm{G}_{1}$-arrested $\mathrm{Y} 1$ cells. Furthermore, $\mathrm{Y} 1$ cell lysates, but not serum-free conditioned medium, possess active FGF-like factors, suggesting that $\mathrm{Y} 1$ cells do not liberate this kind of factors into the culture medium.

\section{Short pulses of ACTH can elicit a weak mitogenic response in $\mathrm{Y} 1$ adrenocortical cells}

Short pulses (up to $2 \mathrm{~h}$ ) of synthetic $\mathrm{ACTH}_{39}$ and natural porcine corticotropin $\mathrm{A}$, at physiological concentrations, trigger DNA synthesis stimulation in $\mathrm{G}_{0} / \mathrm{G}_{1}$-arrested Y1 adrenocortical cells. In a 24-h experiment, a 2-h pulse of $1 \mathrm{nM} \mathrm{ACTH} 39$ or 0.1 $\mathrm{mU} / \mathrm{ml}$ corticotropin A respectively leads to a 2.6- and 2.5-fold increase in BrdU-labeling index; under the same conditions, $0.2 \mathrm{nM}$ FGF2 causes a 7-fold increase in BrdUlabeling index. This mitogenic activity of ACTH is not dependent on the cAMP/PKA pathway, since it is observed in PKA-deficient mutants of the $\mathrm{Y} 1$ cell line. In addition, ACTH mitogenic activity is inhibited by the PKC inhibitor GF109203X. Thus, according to this mitogenic assay, ACTH resembles FGF2, except that ACTH is a weak mitogen $(2,3)$.

The synthetic ACTH fragment 7-38, a well-known competitive inhibitor of $\mathrm{ACTH}_{39}$ (21), at $100 \mathrm{nM}$ inhibits by $60 \%$ and $80 \%$ the DNA synthesis respectively stimulated by 1 $\mathrm{nM} \mathrm{ACTH}{ }_{39}$ and $1 \mathrm{mU} / \mathrm{ml}$ corticotropin A, indicating that this mitogenic effect of $\mathrm{ACTH}_{39}$ and corticotropin A is mediated by specific ACTH receptors.

Two clear differences between the patterns of mitogenic activity of ACTH and FGF2 should be emphasized. First, experiments to define the dose-response relationship show a sharp difference between ACTH and FGF2: a bell-shaped curve for $\mathrm{ACTH}_{39}$ with a maximum between 0.1 and $1 \mathrm{nM}$ and an asymptotic curve in the range of 0.1 to $1000 \mathrm{pM}$ for FGF2 with an ED50\% of about $0.5 \mathrm{pM}$. Second, for ACTH, mitogenic activ- 
ity decreases sharply beyond $2 \mathrm{~h}$ of pulse length, whereas for FGF2, mitogenic activity is the same for short pulses or sustained treatment.

\section{ACTH induces transcription of the fos and jun genes, but not of the c-myc gene}

$\mathrm{ACTH}$, like FGF2, is a strong inducer of the fos and jun families of proto-oncogenes in $\mathrm{Y} 1$ adrenocortical cells, independently of protein synthesis $(5,6)$. Experiments of runoff transcription have shown that ACTH transiently induces transcription of c-fos, fos $\mathrm{B}, \mathrm{c}-j u n$ and jun $\mathrm{B}$ between 10 and $30 \mathrm{~min}$. Similar results were obtained with FGF2 and PMA (phorbol-12-myristate-13-acetate) in identical experiments of run-off transcription. To further probe into fos and jun induction by signals initiated in ACTH receptors, we took the entire ACTH receptor cDNA, inserted it in the pSVK3 mammalian vector, and transfected it into Balb3T3 fibroblasts (22). Stable 3T3 transfectants, expressing active ACTH receptors, respond to ACTH displaying induction of c-Fos, Fra1, Fra2, cJun and JunB proteins; circumstantial evidence suggests that this induction is independent of the cAMP/PKA pathway. Taken together, these results indicate that ACTH receptors can potentially initiate signals sufficient to induce the whole set of fos and jun genes.

On the other hand, $\mathrm{ACTH}$, in contrast to FGF2, does not have any effect on transcription of the c-myc oncogene in Y1 adrenocortical cells. Thus, with respect to transcription induction of the early response genes, required for $\mathrm{G}_{0} \rightarrow \mathrm{G}_{1} \rightarrow \mathrm{S}$ transition, namely the fos, jun and c-myc genes, ACTH effects are not equal to FGF2 effects. In fact, ACTH post-transcriptionally inhibits the expression of c-myc induced by FGF2, by mechanisms dependent on cAMP/PKA (see below).

We should keep in mind that $\mathrm{Y} 1$ adrenocortical cells are tumor cells whose control of c-myc transcription is partially relaxed, due to amplification and over-expression of the c-Ki-ras proto-oncogene. For these reasons, $\mathrm{Y} 1$ cells serum starved to arrest the cell cycle show significantly high basal levels of c-myc expression, i.e., 20 to $30 \%$ nuclear labeling with anti-c-Myc antibodies. This conclusion is supported by transfections of the N17 dominant negative mutant of c-ras into $\mathrm{Y} 1$ adrenocortical cells that yields stable transfectants displaying a reconstituted tight control of c-myc expression.

\section{c-Fos and C-Jun proteins are mediators of the mitogenic response to both ACTH and FGF2}

To test whether fos and jun induction is necessary for cell entry into the $\mathrm{S}$ phase stimulated by ACTH and FGF2, we blocked c-Fos and c-Jun protein synthesis with antisense phosphorotioate oligodeoxynucleotides (23).

The pattern of antisense inhibition is different for FGF2 and ACTH. Combination of both c-fos and c-jun antisense oligonucleotides is required to completely inhibit DNA synthesis stimulation by FGF2; c-fos or cjun oligonucleotide alone causes only about $50 \%$ inhibition. On the other hand, DNA synthesis stimulated by ACTH is essentially abolished by either c-fos or c-jun antisense oligonucleotides. In spite of these differences in patterns of antisense inhibition, altogether these results support the notion that the induction of c-Fos and c-Jun proteins is a necessary step in the triggering mechanisms by which both ACTH and FGF2 drive $\mathrm{G}_{0} /$ $\mathrm{G}_{1}$-arrested $\mathrm{Y} 1$ adrenal cells to enter the $\mathrm{S}$ phase.

\section{ACTH antagonizes the mitogenic action of FGF2}

Analysis of the interaction between $\mathrm{ACTH}$ and FGF2 has revealed that ACTH antagonizes the mitogenic action of FGF2, 
but the phenomenology of this interaction is complex (3). A 30-min pulse of $1 \mathrm{nM}$ FGF2 causes a 12-fold increase in BrdU-labeling index of $G_{0} / G_{1}$-arrested $Y 1$ cells, after $2 \mathrm{~h}$ incorporation of $1 \mu \mathrm{M}$ BrdU between 12 and $14 \mathrm{~h}$. A 30-min pulse of $100 \mathrm{mU} / \mathrm{ml} \mathrm{ACTH}$, under the same conditions, yields an increase in BrdU-labeling index of only 3fold. But combination of FGF2 with ACTH in the 30-min pulse reduces the mitogenic activity of FGF2 by $50 \%$. On the other hand, a 2-h pulse of ACTH, between 6 and $8 \mathrm{~h}$, after the 30-min initial pulse of FGF2 completely abolishes the mitogenic response of $\mathrm{G}_{0} / \mathrm{G}_{1}$-arrested $\mathrm{Y} 1$ cells. This ACTH inhibition of FGF2 mitogenic activity is dependent on PKA, but its mechanisms are still obscure.

ACTH post-transcriptionally inhibits the expression of c-Myc protein in Y1 adrenocortical cells by a process dependent on PKA. This inhibitory effect is likely to be part of the mechanisms by which ACTH inhibits the mitogenic activity of FGF2. In exponentially growing $\mathrm{Y} 1$ cells, $0.1 \mathrm{nM}$ $\mathrm{ACTH}_{39}$ causes a 3 -fold reduction in \% nuclear labeling with anti-c-Myc antibodies within 15 min. In $\mathrm{G}_{0} / \mathrm{G}_{1}$-arrested $\mathrm{Y} 1$ cells, cMyc levels stimulated by FGF2 (1 nM) decrease anti-c-Myc antibody nuclear labeling from 70 to $30 \%$ within 30 min of $\mathrm{ACTH}_{39}$ (10 nM) treatment. In PKA-deficient mutants of Y1 cells, c-Myc protein expression is completely resistant to $\mathrm{ACTH}_{39}$.

On the other hand, $\mathrm{ACTH}_{39}$ has no effect whatsoever on the induction of cyclin D1 protein by FGF2 in Y1 adrenocortical cells. Intriguingly, commercially available preparations of natural porcine corticotropin $\mathrm{A}$ (100 mU/ml; Sigma Chemical Co., St. Louis, MO, USA) block cyclin D1 induction when added together with FGF2 (1 nM) in a pulse of $1 \mathrm{~h}$. But addition of the same preparation of corticotropin A (100 mU/ml) after the 1-h pulse of FGF2 (1 nM) has no effect on the induction of cyclin D1, detected by Western blot. Apparently, these commercial prepara- tions of corticotropin A contain as a contaminant an unknown small peptide (or peptides) of pituitary origin and distinct from ACTH that blocks cyclin D1 induction by FGF2 in Y1 adrenocortical cells (see below).

\section{ACTH is a poor activator of ERK- MAPK, but a MEK1 inhibitor blocks ACTH mitogenic activity on Y1 adrenocortical cells}

Several lines of evidence suggest that ACTH induces the fos and jun genes and stimulates DNA synthesis in $\mathrm{G}_{0} / \mathrm{G}_{1}$-arrested

A
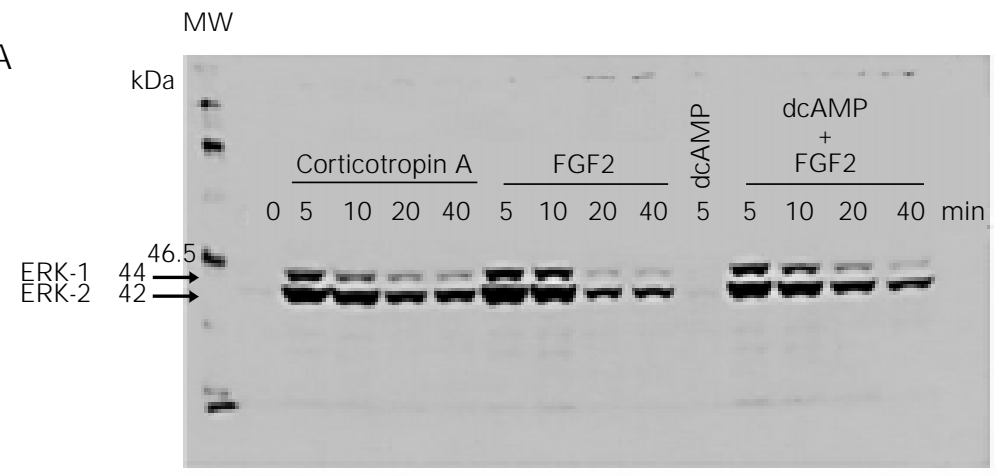

B


Figure 1 - ERK-MAPK activation in Y1 adrenocortical cells assayed by Western blot. A, Kinetics of activation; $100 \mathrm{mU} / \mathrm{ml}$ corticotropin A (Cort A), 1 nM FGF2, 1 mM dibutyryl cAMP (dcAMP). B, Screening of activities of fractions ( $F r) ~ 1$ to 4 of porcine corticotropin A batch 96H0687 (Sigma) fractionated in an HPLC reverse phase column. C, Dose-response curves for the two most active fractions, namely 1 and 2 . Dilution series from 1 to 5 , respectively. Corticotropin A: 100, 1, 0.01 and $0.001 \mathrm{mU} / \mathrm{ml}$; fractions 1 and 2: 10, 0.1, 0.01, 0.001 and $0.0001 \mu \mathrm{g} / \mathrm{ml}$. Cell lysates were boiled for $5 \mathrm{~min}$, submitted to $10 \%$ SDS-PAGE and electroblotted onto nitrocellulose Hybond-C extramembranes (Amersham Life Science Inc., Cleveland, $\mathrm{OH}, \mathrm{USA}$ ). Membranes were incubated with anti-phospho-MAPK rabbit antibody (New England Biolabs Inc., Beverly, MA, USA) and developed by chemiluminescence with HRP-linked anti-rabbit antibody. 
Y1 cells through pathways other than the classical cAMP/PKA pathway. A likely candidate to transduce mitogenic signals initiated in ACTH receptors would be the ERKMAPK pathway.

The phosphorylated forms of ERK1 and ERK2 are not detected in lysates of $\mathrm{G}_{0} / \mathrm{G}_{1^{-}}$ arrested Y1 cells by Western blots, developed with specific antibodies to both ERKphosphorylated forms. FGF2 and corticotropin A rapidly and transiently promote activation of both ERK-MAPK forms with similar kinetics: peaking between 2 and $5 \mathrm{~min}$ and sharply decreasing after 10 min (Figure 1A). cAMP analogs (0.5 to $3 \mathrm{mM}$ ) have no effect on ERK activation promoted by FGF2 (Figure 1A). The synthetic forms of ACTH, $\mathrm{ACTH}_{39}$ and $\mathrm{ACTH}_{24}$, do not duplicate the ERK-activating effect of corticotropin A (Figure $1 \mathrm{C})$, whereas PMA (10 $\mathrm{ng} / \mathrm{ml})$ and fetal

Table 1 - Activities of $\mathrm{ACTH}_{39}, \mathrm{ACTH}_{24}$ and fractions of porcine corticotropin A regulating functions of $Y 1$ adrenocortical cells.

Steroidogenesis was estimated by extracting and assaying the fluorescent steroids liberated by cells into serum-free medium; specific activities were determined from dose-response curves. The unit of activity was arbitrarily defined as the ratio between fluorescence of stimulated cultures over fluorescence of untreated controls. Extracellular signal-regulated kinases-mitogen-activated protein kinases (ERK-MAPK) activation was assayed by Westem blot as described in Figure 1. c-Fos protein induction was estimated by immunocytochemical staining with anti-c-Fos antibodies counting \% labeled nuclei under the microscope. All fractions significantly activated adenylate cyclase but specific activities were not determined. ACTH 39 (EPM) and ACTH $\mathrm{A}_{24}$ (EPM) are peptides synthesized in the laboratory of L. J uliano. $\mathrm{ACTH}_{39}$ (Sigma) is a commercial product. Porcine corticotropin A batch $96 \mathrm{H} 0687$ was purchased from Sigma. All peptide fractions were chemically characterized by HPLC and mass spectrometry and also eventually by $\mathrm{N}$-terminal sequencing. ND: Not determined.

\begin{tabular}{lccc}
\hline $\begin{array}{l}\text { Porcine } \\
\text { corticotropin A }\end{array}$ & $\begin{array}{c}\text { Steroidogenesis } \\
\text { stimulation } \\
\text { (specific activity } \\
\text { arbitrary units) }\end{array}$ & $\begin{array}{c}\text { ERK-MAPK } \\
\text { activation } \\
\text { (specific activity } \\
\text { arbitrary units) }\end{array}$ & $\begin{array}{c}\text { c-Fos protein } \\
\text { induction (maximal } \\
\text { activity; \% labeled } \\
\text { nuclei) }\end{array}$ \\
\hline Total & 20 & 10 & 91 \\
Fraction 1 & 1 & 100 & 91 \\
Fraction 2 & 1 & 5 & 100 \\
Fraction 3 & 1 & $<1$ & 42 \\
Fraction 4 & 10 & $<1$ & 65 \\
ACTH $_{39}$ (EPM) & $>20$ & $<1$ & 25 \\
ACTH $_{24}$ (EPM) & ND & $<1$ & 33 \\
ACTH $_{39}$ (Sigma) & ND & $<1$ & 55 \\
& & &
\end{tabular}

calf serum (10\%) promote maximal activation of both ERK1 and ERK2. This observation agrees with the report by Pestell and collaborators (24) that $\mathrm{ACTH}_{39}$ does not activate ERK-MAPK. Only lysates of Y1 cells treated with high, non-physiological concentrations $(100 \mathrm{nM})$ of both $\mathrm{ACTH}_{39}$ and $\mathrm{ACTH}_{24}$ have shown faint bands of phosphorylated ERK in Western blots (Figure 1C). These results imply that the most active chemical species in corticotropin A, that promotes ERK phosphorylation, is an unknown peptide different from $\mathrm{ACTH}_{39}$ and $\mathrm{ACTH}_{24}$. On the other hand, corticotropin A does not promote phosphorylation of ERK in Balb3T3 fibroblasts, suggesting that the active species of corticotropin A are specific for adrenal cells. As expected, FGF2 is equally active in $\mathrm{Y} 1$ adrenocortical cells and Balb3T3 fibroblasts in promoting ERK phosphorylation.

One batch of a commercial preparation of porcine pituitary corticotropin A was fractionated on a reverse phase HPLC-column and analyzed by mass spectrometry and Nterminal sequencing. $\mathrm{ACTH}_{39}$, representing $40 \%$ of the total, is the major component and was isolated in a single homogeneous fraction (fraction 4). Other identified major components were $3 \mathrm{MSH}$ (fraction 3 ) and $\gamma \mathrm{MSH}$ (fraction 2), which are not active on Y1 cells. Fraction 1 displays 6 peaks that were not chemically identified. Fraction 1 shows the highest activity for promotion of ERK-MAPK phosphorylation (Figure 1B and C) and the lowest activity for steroidogenesis stimulation (Table 1).

The MEK inhibitor, PD98059 $(50 \mu \mathrm{M})$, strongly inhibits ERK phosphorylation promoted by corticotropin A and PMA in Y1 adrenal cells. In addition, as expected, 50 $\mu \mathrm{M}$ PD98059 inhibits at least $80 \%$ of the DNA synthesis stimulated by $100 \mathrm{mU} / \mathrm{ml}$ corticotropin A. Unexpectedly, $50 \mu \mathrm{M}$ PD98059 turns out to be also a strong inhibitor of both DNA synthesis stimulation and c-Fos induction by the synthetics $\mathrm{ACTH}_{39}$ 
and $\mathrm{ACTH}_{24}$, in spite of the fact that these synthetic forms of ACTH are comparatively poor activators of ERK phosphorylation.

\section{Conclusions}

FGF2 elicits a prototypic mitogenic response in $\mathrm{Y} 1$ adrenocortical cells that cannot be triggered by signals initiated in $\mathrm{ACTH}$ receptors.

Taken together, the results reviewed here suggest that the weak mitogenic response of Y1 adrenocortical cells to ACTH, whose unmasking we recently reported (3), consists of the following sequential steps: a) initiation of signals in ACTH receptors, b) activation of PKC, c) activation of ERKMAPK, d) induction of fos and jun genes, and e) stimulation of entry of $\mathrm{G}_{0} / \mathrm{G}_{1}$-arrested cells into the $\mathrm{S}$ phase of cell cycle.

Signals initiated in ACTH receptors and transduced by the cAMP/PKA pathway posttranscriptionally down-regulate c-Myc protein expression, typifying an efficient mechanism of growth inhibition.

We are still missing important links to explain the mechanisms that underlie the correlation between chronically elevated levels of circulating ACTH and, for instance, the adrenal cortex hyperplasia well documented in classical inborn errors of steroidogenesis (25).

\section{References}

1. Hornsby PJ (1985). Regulation of adrenocortical cell proliferation in culture. Endocrine Research, 10: 259-281.

2. Armelin HA, Lotfi CFP \& Lepique AP (1996). Regulation of growth by ACTH in the $Y-1$ line of mouse adrenocortical cells. Endocrine Research, 22: 373-383.

3. Lotfi CFP, Todorovic Z, Armelin HA \& Schimmer BP (1997). Unmasking a growth-promoting effect of the ACTH in Y1 mouse adrenocortical tumor cells. J ournal of Biological Chemistry, 272: 29886-29891.

4. Gutkind J S (1998). The pathways connecting $\mathrm{G}$ protein-coupled receptors to the nucleus through divergent mitogen-activated protein kinase cascades. J ournal of Biological Chemistry, 273: 1839-1842.

5. Kimura E \& Armelin HA (1990). Phorbol ester mimics ACTH action in corticoadrenal cells stimulating steroidogenesis, blocking cell cycle, changing cell shape and inducing c-fos proto-oncogene expression. J ournal of Biological Chemistry, 265: 3518-3521.

6. Kimura E, Sonobe MHH, Armelin MCS \& Armelin HA (1993). Induction of FOS and J UN proteins by adrenocorticotropin and phorbol ester but not by $3^{\prime}, 5^{\prime}$-cyclic adenosine monophosphate derivatives. Molecular Endocrinology, 7: 1463-1471.

7. Angel P \& Karin M (1991). The role of J un, Fos and the AP-1 complex in cell-prolif- eration and transformation. Biochimica et Biophysica Acta, 1072: 129-157.

8. Holt J T, Gopal TV, Moulton AD \& Nienhuis AW (1986). Inducible production of c-fos antisense RNA inhibits 3T3 cell proliferation. Proceedings of the National Academy of Sciences, USA, 83: 4794-4798.

9. Riabowol KT, Vosatka R, Ziff EB, Lamb NJ \& Feramisco J R (1988). Microinjection of fos-specific antibodies blocks DNA synthesis in fibroblast cells. Molecular and Cellular Biology, 8: 1670-1676.

10. Kovary K \& Bravo R (1991). The J un and Fos protein families are both required for cell cycle progression in fibroblasts. Molecular and Cellular Biology, 11: 44664472.

11. Burgess WH \& Maciag T (1989). The heparin-binding fibroblast growth factor family of proteins. Annual Review of Biochemistry, 58: 575-606.

12. Nishimura $\mathrm{T}$, Utsunomiya $\mathrm{Y}$, Hoshikawa M, Ohuchi H \& Itoh N (1999). Structure and expression of a novel human FGF, FGF19, expressed in fetal brain. Biochimica et Biophysica Acta, 1444: 148-151.

13. Meyers EN \& Martin GR (1999). Differences in left-right axis pathways in mouse and chick: functions of FGF8 and SHH. Science, 285: 403-406.

14. J ung J , Zheng $M$, Goldfarb $M \&$ Zaret KS (1999). Initiation of mammalian liver development from endoderm by fibroblast growth factors. Science, 284: 1998-2003.

15. Metzger RJ \& Krasnow MA (1999). Genetic control of branching morphogenesis. Science, 284: 1635-1639.

16. Miralles F, Czernichow $P$, Ozaki $K$, Itoh $N$ \& Scharfman R (1999). Signaling through FGF receptor $2 b$ plays a key role in the development of the exocrine pancreas. Proceedings of the National Academy of Sciences, USA, 96: 6267-6272.

17. Mesiano S, Mellon SH, Gospodarowicz D, DiBlasio AM \& J affe RB (1991). Basic FGF expression is regulated by corticotropin in the human fetal adrenal - a model for adrenal growth regulation. Proceedings of the National Academy of Sciences, USA 88: 5428-5432.

18. Schimmer BP (1981). The adrenocortical tumor cell line, Y-1. In: Sato G (Editor), Functionally Differentiated Cell Lines. Alan R. Liss, Inc., New York, 61-92.

19. Rae PA, Gutmann NS, Tsao \& \& Schimmer BP (1979). Mutations in cyclic AMP-dependent protein kinase and corticotropin (ACTH)-sensitive adenylate cyclase affect adrenal steroidogenesis. Proceedings of the National Academy of Sciences, USA, 76: 1896-1900.

20. Schimmer BP \& Parker KL (1992). Promoter elements of the mouse 21-hydroxylase (Cyp-21) gene involved in cell-selective and CAMP-dependent gene expression. J ournal of Steroid Biochemistry and 
Molecular Biology, 43: 937-950.

21. Li CH, Chung D, Yamashiro D \& Lee CY (1978). Isolation, characterization and synthesis of a corticotropin-inhibiting peptide from human pituitary glands. Proceedings of the National Academy of Sciences, USA, 75: 4306-4309.

22. Forti FL \& Armelin HA (1998). ACTH in- duces c-fos proto-oncogene in fibroblasts expressing the $\mathrm{ACTH}$ receptor. Endocrine Research, 24: 433-437.

23. Lotfi CFP \& Armelin HA (1998). c-Fos protein is a mediator in mitogenic response to ACTH. Endocrine Research, 24: 421424.

24. Watanabe G, Pena P, Albanese C,
Wilsbacher LD, Young JB \& Pestell RG (1997). Adrenocorticotropin induction of stress-activated protein kinase in the adrenal cortex in vivo. J ournal of Biological Chemistry, 272: 20063-20069.

25. New MI (1998). Diagnosis and management of congenital adrenal hyperplasia. Annual Review of Medicine, 49: 311-328. 